\section{Lassa fever - full recovery without ribavarin treatment: a case report}

Nnennaya A. Ajayi ${ }^{1}$, Kingsley N. Ukwaja ${ }^{1}$, Ngozi A. Ifebunandu $^{1}$,

Richard Nnabu', Francis I. Onwe, ${ }^{2,3}$, Danny A. Asogun

1. Department of Internal Medicine, Federal Teaching Hospital Abakaliki, Ebonyi State, Nigeria

2. Department of Community Medicine, Federal Teaching Hospital Abakaliki, Ebonyi State, Nigeria

3. Epidemiology Unit, Ministry of Health, Ebonyi State, Nigeria

4. Institute of Lassa Fever Research and Control, Irrua Specialist Teaching Hospital, Edo State, Nigeria

\section{Abstract}

Background: Lassa fever is a rodent-borne zoonosis that clinically manifests as an acute hemorrhagic fever. It is treated using ribavarin. Surviving Lassa fever without receiving the antiviral drug ribavarin is rare. Only few cases have been documented to date.

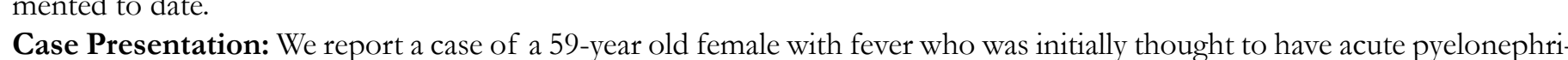
tis and sepsis syndrome with background malaria. Further changes in her clinical state and laboratory tests led to a suspicion tis and sepsis syndrome with background malaria. Further changes in her clinical state and laboratory tests led to a suspicion
of Lassa fever. However at the time her laboratory confirmatory test for Lassa fever returned, her clinical state had improved of Lassa fever. However at the time her laboratory confirmatory test for Lassa fever returned, her clinical state had improved
and she made full recovery without receiving ribavarin. Her close contacts showed no evidence of Lassa virus infection. Conclusion: This report adds to the literature on the natural history of Lassa fever; and that individuals may survive Lassa fever with conservative management of symptoms of the disease and its complications.

Keywords: Lassa fever; viral hemorrhagic fever, survival, ribavarin

DOI: http://dx.doi.org/10.4314/ahs.v14i4.40

\section{Introduction} fests as an acute viral hemorrhagic fever. It was first ed 19 States of the federation includes Ebonyi State ${ }^{3}$ described in northeastern Nigeria in 1969, and it is ${ }^{4}$. Majority of the earliest cases of Lassa fever died ${ }^{5}$ endemic in West Africa ${ }^{1}$. The animal reservoir of the Only one of these early laboratory confirmed case was Lassa fever virus is a rat, Mastomys natalensis. Trans- documented to have survived with supportive therapy mission occurs through direct exposure to the excreta/ alone ${ }^{1}$. Early attempts at treating Lassa fever involved blood of infected rats, or from person to person via total isolation and supportive therapy with or withbody fluids. The incubation period ranges between 7 to out the use of the convalescent serum or antibody $y^{5,6}$ 18 days $^{2}$. In endemic areas, an estimated 300,000 - 500, Presently, Lassa fever management involves the use of 000 cases and 5000 to 10,000 deaths occur annually ${ }^{3}$. ribavarin, supportive therapy, and simple barrier nursAbout $80 \%$ of persons infected with the Lassa virus ing usually in a specific ward dedicated for the disease 6 are asymptomatic; but in the remaining $20 \%$, the illness Treatment with intravenous ribavarin is particularly usemanifests as a febrile illness of variable severity associ- ful in decreasing Lassa fever mortality - its administraated with multiple organ dysfunctions with or without tion within the first 6 days of illness has been shown to hemorrhage ${ }^{1-3}$.

\section{Corresponding author:}

Kingsley N. Ukwaja

Department of Internal Medicine,

Federal Teaching Hospital,

Abakaliki, Ebonyi State, Nigeria

Tel: +234 08036243196;

E-mail: ukwajakingsley@yahoo.co.uk and resides in Ebonyi State, Nigeria. She was admitted with a one week history of fever, shaking chills, severe headaches, anorexia and body weakness. On the day of presentation, she had two episodes of vomiting but no hematemesis. She admitted to taking meals of game that often included rat meat. Before presentation, she visited a district hospital where she was treated with intravenous quinine and chloramphenicol and at presentation she was on oral antimalarials (artemether-lumefantrine) and ciprofloxacin without improvement. She was a known hypertensive diagnosed three years ago; and had been compliant with her anti-hypertensives.

On examination, she had a temperature $(\mathrm{T})$ of $39.1^{\circ} \mathrm{C}$ and was moderately pale; pulse rate was 78 beats per

minute and blood pressure $130 / 80 \mathrm{mmHg}$. Her respiratory rate was 32 cycles per minute; other component the chest and neurologic examinations were unremarkable. On abdominal examination, she had hepatomegally and bilateral loin tenderness. A diagnosis of acute pyelonephritis and sepsis syndrome with background poorly treated malaria was made. Blood samples were collected for blood culture, complete blood count and film for malaria parasites, serum electrolytes, urea and creatinine, hepatic enzymes, urinalysis and urine microscopy, culture and sensitivity. She continued her oral antimalarials, antibiotic, and antihypertensive as well as intravenous fluid infusion. Her urinalysis showed massive hematuria $(+++)$, proteinuria $(++)$, glucose $(+)$ bacteruria $(++)$ and granular cast $(++)$. The blood ex-

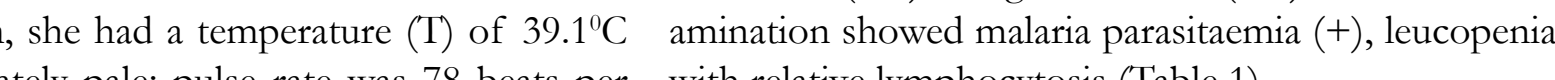
with relative lymphocytosis (Table 1).

Table 1: Complete blood count changes in an individual with confirmed Lassa fever

\begin{tabular}{llllllll}
\hline Variables & Day 1 & Day 4 & Day 8 & Day 11 & Day 15 & $\begin{array}{l}\text { After 2 } \\
\text { weeks }\end{array}$ \\
& & & & & & Reference value \\
\hline Hemoglobin & 12 & 8.3 & 9 & 9.3 & 9.6 & 10 & $12-16 \mathrm{~g} / \mathrm{dl}$ \\
WBC count & 1.7 & 4.2 & 4.4 & 6.0 & 6.2 & 5.2 & $4-11 \times 10^{9}$ cells / liter \\
Neutrophils & 48 & 16 & 13 & 30 & 50 & 43 & $40-70 \%$ \\
Lymphocytes & 52 & 84 & 84 & 70 & 50 & 55 & $20-40 \%$ \\
Eosinophils & 0 & 02 & 01 & 0 & 0 & 2 & $1-6 \%$ \\
Monocytes & 0 & 0 & 02 & 0 & 0 & 0 & $2-10 \%$ \\
Basophils & 0 & 0 & 0 & 0 & 0 & 0 & $0-1 \%$ \\
Thrombocytes & 80 & 62 & 102 & 130 & 149 & - & $150-400 \times 10^{9} /$ liter \\
Malaria parasite & $(+)$ & $(+)$ & $(-)$ & $(-)$ & $(-)$ & - & Positive $(+) /$ negative $(-)$ \\
Reticulocyte count & - & 0.6 & 1.3 & 1.4 & - & - & $0.2-2.0$ \\
\hline
\end{tabular}


Also, her serum hepatic enzymes were elevated (aspartate aminotransferase, 101 IU per liter; alanine aminotransferase, $68 \mathrm{IU}$ per liter). However, blood culture, serum bilirubin, urea and creatinine were unremarkable.

Three days later, the fever persisted $\left(\mathrm{T}, 39^{\circ} \mathrm{C}\right)$, and she developed noisy breathing. On examination, she had coarse crackles at her lung bases, and rhonchi all ove her lung zones. The oral antibiotics were stopped and she was commenced on intravenous amoxicillin-clavulanic acid, and later ceftazidime, and intravenous artesunate. On the 8th day of admission, she still had feve $\left(\mathrm{T}, 38.2^{\circ} \mathrm{C}\right)$, but no longer had loin pains and headaches. A repeat $\mathrm{CBC}$ showed anaemia, neutropenia, massive lymphocytosis and thrombocytopenia (Table 1); however, malaria parasites were absent. The Lassa fever management team was invited. Following review, a diagnosis of suspected Lassa fever was made. The patient blood sample was sent for Lassa virus-specific reverse transcriptase polymerase chain reaction (RT-PCR) using previously described methods

Over the next three days, she had a gradual fall in temperature. On the 11th day of admission, she complained of numbness on her feet, and her temperature had fallen to $37.4^{\circ} \mathrm{C}$. The noisy breathing and abdominal pain has resolved. On that day, her Lassa virus-specific RTPCR test results returned and the diagnosis of Lassa fever was confirmed. Due to her improving clinical state, intravenous ribavarin was not commenced; but, her temperature was monitored closely. The intravenous antibiotics were continued with oral vitamin Bcomplex. The numbness resolved on the 14th day of admission. Two repeat $\mathrm{CBC}$ done on the 11th and 15th day of admission showed improving indices (Table 1). The patient was discharged on the 18th day of admission. On follow-up visits two and four weeks after discharge, she remained well. A CBC done two weeks after discharge showed further improving hematologic indices (Table 1). Presently, she has a monthly follow-up appointment.

Sixteen individuals found to be high-risk contacts of the patient were screened but showed no evidence of Lassa virus infection.

\section{Discussion}

Surviving Lassa fever without antiviral treatment using ribavarin is perceived to be rare. Only one individua has been documented to have survived without receiving the anti-viral agent ribavatin ${ }^{1}$ Others, who had survived without receiving ribavarin were not confirmed ${ }^{9}$ and if confirmed, were either given serum of the Lassa fever survivor ${ }^{5}$, or had scanty information on how the were managed ${ }^{2}$. At presentation, our patient's signs and symptoms were insufficient to consider a differentia diagnosis of "suspected Lassa fever"7. But, given that she still had malaria parasitaemia and bacteruria, Lassa fever suspicion was given less consideration. However the persistence of severe fever despite receiving various antimalarials and antibiotics as well as evidence of clearance of picion of Lassa fever. The first documented survivo of Lassa fever also received empirical antimalarials and antibiotics despite no evidence of bacteria or plasmodium infection ${ }^{1}$. It is possible that these agents may have some effect on the pathophysiology of Lassa fever.

At the time of the confirmation of Lassa fever, the patient's clinical state had substantially improved; hence ribavarin was not given to her. Moreover, the patien had features that are known adverse effects of ribavarin; anaemia, rigors, nausea and vomiting, abdominal pain, fatigue, and headache ${ }^{10}$, were key symptoms the patient presented with. If ribavarin was administered and he clinical state deteriorates, it will be difficult to differentiate between the adverse effects of ribavarin and worsening of the Iassa fever. The Lassa virus-specific RTPCR used to confirm the diagnosis is the gold standard for Lassa fever confirmation. Also, the RT- PCR assay currently in use in Nigeria has 100\% sensitivity in detecting the local strains of the Lassa virus ${ }^{11}$. She had an admission AST of 101 I.U per liter, a previous study has shown that hospitalized Lassa fever cases with admission AST $\geq 150$ IU per liter have increased mortal ity $^{6}$. Our report suggests that a patient with laboratory confirmed Lassa fever with falling temperature, low admission AST $<150$ IU per liter and improving clinical state may not require treatment with ribavarin.

None of the individuals classified as a high-risk contac of the patient had evidence of Lassa virus infection. Also, none of the health workers who participated in the management of the patient were infected. This agrees with previous findings that Lassa virus is not as infectious as it is always suspected-previous observations have shown that even repeated, often intimate contact of Lassa fever patients described by family member often fail to transmit the infection ${ }^{12,13}$. It was not pos- sible to demonstrate other changes in the patient's biochemical parameters during recovery and discharge due to high treatment costs.

Future research needs to be conducted in communities with Lassa fever to identify individuals with high circulating immunoglobulin-G antibodies to the Lassa virus i.e. those who might have had clinical or subclinical infection and recovered. Identified cases needs to be evaluated to determine the factors associated with survival Furthermore, they should be followed in a cohort study to determine if past infection with Lassa virus affects the risk of recurrence, re-infection, or clinical presentation of other diseases which manifests with fever.

\section{Conclusion}

This report adds to the literature on the natural history of Lassa fever. It suggests that conservative management of symptoms of the disease and its complication may improve survival of individuals infected with Lassa fever. There is need for the development of reliable point of care tools in order to quickly confirm or rule out the diagnosis of Lassa fever, and other viral hemorrhagic fevers once suspected. This is the next challenge in tackling Lassa, Ebola, and Marburg hemorrhagic fevers in Africa ${ }^{14}$.

\section{Conflict of interest statement:}

The authors have no conflict of interest to declare

\section{Funding:}

No specific funding was received for the study.

\section{Acknowledgement:}

We thank Prof Stephan Günter of the Department of Virology, Bernhard-Nocht-Institute, Germany for performing the confirmatory laboratory test. The Department of Virology of the Bernhard-Nocht-Institute is a WHO Collaborating Centre for Arbovirus and Haemorrhagic Fever Reference and Research.

\section{References}

1. Frame JD, Baldwin JM, Gocke DJ, Troup JM. Lassa fever, a new virus disease of man from West Africa. I. Clinical description and pathological findings. $A m$ Trop Med Hyg 1970; 19 (4): 670-6.

2. McCormick JB, King IJ, Webb PA, Johnson KM O'Sullivan R, Smith ES, et al. A case- control study of the clinical diagnosis and course of Lassa fever. J Infect Dis 1987; 155 (3): 445-55.
3. Ogbu O, Ajuluchukwu E, Uneke CJ. Lassa fever in West Africa sub region: an overview. I Vect Borne Dis 2007; 44 (1): 1-11

4. Ajayi NA, Nwigwe CG, Azuogu BN, Onyire BN, Nwonwu EU, Ogbonnaya LU, et al. Containing a Lassa fever epidemic in a resource-limited setting: outbreak description and lessons learned from Abakaliki, Nigeria (January-March 2012). Int I Infect Dis 2013; 17: e1011 e1016

5. Leifer E, Gocke DJ, Bourne H. Lassa fever, a new virus disease of man from West Africa. II. Report of a laboratory-acquired infection treated with plasma from a person recently recovered from the disease. Am J Trop Med Hyg 1970; 19 (4): 677-9

6. McCormick JB, King IJ, Webb PA, Scribner CL, Craven RB, Johnson KM, et al. Lassa fever: effective therapy with ribavarin. N Engl J Med 1986; 314 (1): 20-26

7. Centers for Disease Control and Prevention and World Health Organization. Technical guidelines for integrated disease surveillance and response in the African region. Atlanta: Center for Disease Control and Prevention, 2010:1-416

8. Asogun DA, Adomeh DI, Ehimuan J, Odia I, Hass $\mathrm{M}$, Gabriel M, et al. Molecular diagnostics for lassa fever at Irrua specialist teaching hospital, Nigeria: lessons learnt from two years of laboratory operation. PLoS Negl Trop Dis 2012; 6 (9): e1839

9. Troup JM, White HA, Fom AL, Carey DE. An outbreak of Lassa fever on the Jos plateau, Nigeria, in January-February 1970. A preliminary report. Am J Trop Med Hyg 1970; 19 (4): 695-6.

10. Bausch DG, Hadi CM, Khan SH, Lertora JJ. Review of the literature and proposed guidelines for the use of oral ribavarin as post-exposure prophylaxis for Lassa fever. Clin Infect Dis 2010; 51 (12): 1435-41

1. Olschläger S, Lelke M, Emmerich P, Panning M, Drosten C, Hass M, et al., Improved detection of Lassa virus by reverse transcription-PCR targeting the $5^{\prime}$ region of S RNA. J Clin Microbiol 2010; 48 (6): 2009-13.

12. Haas WH, Breuer T, Pfaff G, Schmitz H, Köhlet P, Asper M et al., Imported Lassa fever in Germany: surveillance and management of contact persons. Clin Infect Dis 2003; 36 (10): 1254-1258

13. Helmick CG, Webb PA, Scribner CL, Krebs JW, McCormick JB. No evidence for increased risk of Lassa fever infection in hospital staff. Lancet 1986; 2 (8517): 1202-1205

14. Mbonye A, Wamala J, Winyi-Kaboyo, Tugumizemo V, Aceng J, Makumbi I. Repeated outbreaks of viral hemorrhagic fevers in Uganda. Afr Health Sci 2012; 12 (4): 579-83. 